\section{Entre dispositivos. Currículo y Tecnología}

Camilo Páez Vanegas*

Resumen: La innegable filiación entre la fotografía y la tecnología han constituido un currículo convulsionado que suele estar desfasado de su contexto. Esta condición hace de los programas de fotografía herederos de otras tradiciones curriculares, anulando la posibilidad de la construcción de contenidos propios en el campo, lo que repercute en un fenómeno endogámico visual en el que se repiten tendencias de forma constante, propio de estos tiempos en los que lo sistemas políticos y económicos se decantan por sociedades no de ciudadanos sino de consumidores. La alternativa es indagar en el contexto y hacer de este currículo invisible uno activo que permeé la estructura institucional y lo acerque a lo cotidiano.

Palabras clave: Educación en fotografía - Fotografía en Colombia - dispositivo - aprendizaje currículo

[Resúmenes en inglés y portugués en las páginas 126 - 127]

${ }^{(*)}$ Diseñador gráfico. Universidad Nacional de Colombia. Bogotá. Especialista en Gestión Estratégica de Diseño. Universidad de Buenos Aires. Maestro en Educación. Universidad de los Andes. Bogotá. Profesor Asociado de la Escuela de Diseño, Fotografía y Realización Audiovisual de la Universidad Jorge Tadeo Lozano (UJTL) desde el año 2010, ha desempeñado su actividad académica en el campo de la Fotografía. Actualmente participa como parte de la coordinación curricular del programa profesional de Fotografía, a partir de su campo de investigación en estudios curriculares. Como diseñador gráfico se ha desempeñado en el campo editorial, principalmente en el área de las publicaciones académicas en la Universidad Nacional de Colombia y en la UJTL.

\title{
Introducción
}

I'm the operator With my pocket calculator

I'm the operator With my pocket calculator

I am adding 
And subtracting

I'm controlling

And composing

Kraftwerk. Pocket calculator. 1981

La relación entre los dispositivos para ver y crear imágenes con los usuarios/espectadores ha vivido una acelerada transformación desde la popularización de la fotografía, oficializada en 1839. En esta carrera las nociones de registro, memoria, durabilidad, eternidad se han transformado para dar paso a la mutabilidad, temporalidad y ubicuidad (Brea, 2010). Lo digital, la pérdida de adherencia material al sustrato, hace del actual espectador un usuario que ejerce el rol de consumidor, y a la vez participante de la constate creación a gran escala de imágenes que se condensan en lo inmaterial del fichero electrónico con un sin fin de usos y usuarios.

En este contexto, la educación en fotografía se enfrenta al reto de acomodar sus estructuras a las dinámicas contemporáneas de la imagen, en las que los participantes de los procesos de aprendizaje ya no son el objeto del proceso educativo sino son sujetos que participan en múltiples esferas y que, como la e-Imagen, son mutables, temporales y ubicuos. En el campo de la enseñanza de la fotografía, las estructuras curriculares se enfrentan a un contexto particularmente cambiante, debido a su intrínseca filiación al dispositivo fotográfico ${ }^{1}$.

\section{Tendencia y uniformidad. La no ideología}

Un hombre en un restaurante toma una foto de su plato de comida antes de siquiera probarlo; junto a su mesa hacen una imagen de un grupo sonriente en pose deliberada de celebración; en la esquina una muchacha elige el filtro de beauty y abraza a su amiga mientras estiran la boca en gesto de pato para una selfie; todas imágenes que se publicarán de inmediato en redes.

La proliferación de dispositivos fotográficos digitales a finales de la década de 1990 y el surgimiento de las redes sociales con la primera década del siglo, fueron factores determinantes para un nuevo periodo en la historia de la imagen fotográfica, en el que la publicación de imágenes y su difusión dejó de ser exclusividad de los de los medios, de masas, editoriales o de comunicación. Esta nueva posibilidad de lo individual en un entorno global ha devenido en un fenómeno endogámico, en el que la creación de imágenes está definida por las aplicaciones tecnológicas y uniformadas por la repetición de tendencias estilísticas, dejando a un lado la intención de construcción de cualquier discurso visual, al menos no de uno previamente estereotipado.

Con la finalización de la guerra fría, tras la caída del muro de Berlín, la última década del siglo XX se apresuró a la propuesta de un nuevo mundo supuestamente alejado de absolutismos, con la idea de una democracia liberal como paradigma de un mundo libre e igualitario en el que la voz de lo personal recobraba un derecho inusual. Este orden mundial antes que traer tranquilidad y libre desarrollo de los individuos, promovió la uniformidad y la reiteración de discursos ideológicos. Mark Fisher (2017) trae a colación la idea de posmodernismo de Jameson que define el fracaso del futuro como constitutivo de la escena 
cultural posmoderna, compuesta por revivals y pastiches (p. 28). Así el realismo capitalista, como denomina Fisher a este periodo neoliberal, se presenta como un todo sin alternativas, haciendo del ciudadano un consumidor dependiente del libre mercado, donde la libertad está enmarcada por la libre competencia. Cualquier posible atisbo de reacción es apropiado por el capitalismo para ser encasillado en tendencias y estilos que a su vez terminan siendo producto de consumo. De esta manera, el gesto de protesta del jugador de fútbol americano Kaepernic es apropiado como una campaña publicitaria de una marca de zapatillas; o el grafiti, otrora expresión social y política, termina siendo parte de campañas corporativas y del circuito comercial artístico. La ruptura ideológica es asimilada y convertida en anécdota por un sistema que precisamente muta por declararse no ideológico.

Siendo este el contexto, su impacto se hace evidente en la palpable desconexión o desinterés del conjunto de los nativos digitales con cualquier posición. La participación social se vive del mismo modo momentáneo y mutable. Fisher se adentra en la falta de compromiso político de las nuevas generaciones británicas, identificándola como impotencia reflexiva, en la que los estudiantes suelen ser encasillados en patologías mentales, como depresión y dislexia, ocluyendo cualquier capacidad de discusión política. Este estado se identifica como una hedonia depresiva, un estado de búsqueda casi que exclusiva de placer, situación derivada de la ambigüedad de las estructuras educativas, en las que el estudiante cambió su rol de sujeto de la institución académica a un rol de consumidor de servicios, con una oferta constante y ante la que no tiene ningún tipo de compromiso personal de vida (p. 49). En consecuencia, este estado es una privación de la condición política del individuo, suprimiendo el discurso personal y la posibilidad de elaborar retóricas, lo que acarrea una imposibilidad reflexiva sobre la imagen, tanto en el consumo como en la creación haciendo del control algo digerible, indiscutible y cotidiano. Así las cosas, no es de extrañar que pese a los años de luchas por causas como por ejemplo la igualdad de género y aun cuando se vuelven virales las imágenes de protestas y bienintencionados hashtags, la publicidad aún replica modelos de mujeres amables de pelo largo castamente vestidas en colores pasteles mientras recibe a sus hijos (un niño y una niña) y a su marido al final de sus jornadas productivas para darles de comer y organizar la ropa limpia del siguiente día. Los bajos índices de calidad en las capacidades lectoras y escritoras que percibimos en muchos estudiantes universitarios son el caldo de cultivo ideal para estos discursos y se decantan en la uniformización de la imagen, aunado con la hedonia depresiva fomentada por redes y entornos sociales que sesgan los juicios más en pareceres que en hechos.

Por lo tanto, cabe preguntarse qué está haciendo la educación formal en general y en particular las escuelas de la imagen en este contexto, en el que se enfrentan a estas dinámicas del entorno en que hay más capacidad de producción (proliferación de dispositivos fotográficos) pero los discursos visuales se hacen cada vez más uniformes y carentes de significado.

\section{Dispositivos y contexto}

Según la definición de Agamben, un dispositivo es "todo aquello que tiene, de una manera u otra, la capacidad de capturar, orientar, determinar, interceptar, modelar, controlar y asegurar los gestos, las conductas, las opiniones y los discursos de los seres vivos" (2011, 
p. 257). De este modo, el dispositivo se presenta también en los elementos cotidianos que modelan desde la historia el comportamiento humano, oponiendo la naturaleza del individuo y el positivismo en una dialéctica de la libertad y el mandato (p. 252). Y así tanto el lenguaje como los artefactos, los medios, las tecnologías y todas las actividades desarrolladas desde el concepto de racionalidad, comunidad y civilización son en sí dispositivos y redes que desarrollan la formación de poder y saber, desde prisiones hasta instituciones académicas, incluyendo el currículo.

Visto desde esta perspectiva se hace posible entonces identificar una relación de tensión entre dos dispositivos: por una parte, el tecnológico, vinculado intrínsecamente a la fotografía y, por otra parte, el currículo académico. Históricamente, el aprendizaje del oficio de la fotografía se inició en un entorno informal, pasando luego a un espacio académico universitario primero en asignaturas y luego en carreras técnicas o tecnológicas, siendo sólo recientemente incluida la formación de nivel profesional en el campo de la imagen fotográfica, particularmente en Colombia.

No obstante, esta incorporación obedeció principalmente a las expectativas de aspirantes y egresados ante las exigencias actuales de titulaciones de grado y posgrado por parte del mercado institucional. En consecuencia, el dispositivo curricular universitario se ha definido priorizando las necesidades del medio laboral, haciendo que los programas académicos se conformen desde tradiciones curriculares heredadas en las que se aplican fórmulas que entienden las necesidades empresariales y comerciales como la proyección del individuo, mantenido al margen de las necesidades o inquietudes personales de los estudiantes. Como consecuencia, la conformación de programas académicos se ha cimentado en las tradiciones heredadas de otras estructuras curriculares en las que se aplican fórmulas que han respondido a las necesidades del medio laboral. Goodson (2000) vincula la estructura curricular preactiva con la noción de tradición heredada de Hobsbawm en el que las prácticas intentan diseminar valores y reglas de forma ritual desde la repetición, generando una noción de continuidad con el pasado y de arraigo (2012, p. 9). Por lo tanto, las estructuras académicas responden más por una filiación a un medio económico que al contexto de sus participantes:

Esto se debe en gran medida a que los grupos de disciplinas empelan un discurso con el que intentan cada vez más que su disciplina se considere «académica» (pudiendo así reclamar los consiguientes recursos financieros y perspectivas profesionales). El corolario de este reclamo es que a los académicos se les debe entregar el control de la definición de «disciplina» (...) De esta manera las diferencias se deben a quien puede definir las disciplinas, lo que se presenta como la actividad característica de los progresos universitarios (Goodson, 2000, p. 66)

De esta manera, las construcciones curriculares se convierten en dispositivos que regulan la naturaleza de la práctica académica, en las que los contenidos no son concebidos directamente del contexto de sus prácticas sino de una tradición formulada, una estructura preactiva (p.54) que surge de las necesidades de la administración académica. El currículo de la fotografía se ha planteado desde fórmulas aplicadas del diseño, las artes plásticas y la 
publicidad sin tomar en cuenta sus prácticas en el entorno social y adquiriendo un cariz didáctico ${ }^{2}$, ajeno a los contextos que los estudiantes viven en medio del cambio tecnológico. La relación entre el dispositivo tecnológico y el dispositivo curricular en la educación fotográfica ha estado mediada por la aceptación renuente de nuevos recursos y medios con gran dificultad, la reticencia a nuevas formas de producción visual y la lenta asimilación de la inminente transformación del medio, al pasar del predominio de la imagen latente del proceso químico a la incertidumbre tecnológica del medio digital. La desacralización de un proceso que antaño era mediado por acciones de orden físico-químico y que implicaba una capacitación rigurosa, ahora es reemplazado por un proceso que mayormente es mediado por un solo entorno y que no implica, a primera vista, mayor especialización o conocimiento por el usuario.

El dispositivo curricular, como un intermediario replicante de estos fenómenos, se alinea con las necesidades del medio y amplía cada vez más la brecha entre lo que pasa en el espacio académico, (una estructura cada vez más definida por su comportamiento burocrático en el sentido estricto del término administrativo $)^{3}$ y el contexto orgánico en el que los dispositivos tecnológicos generan constantemente diferentes dinámicas e interacciones.

Este desfase entre dispositivos, el curricular y el tecnológico, revela un carácter alienante de la institución académica, en que la premisa es instruir adentro para funcionar afuera y hace de la aplicación de fórmulas la ruta más eficaz para la enseñanza. Las tradiciones curriculares se decantan de forma piramidal y las herramientas tecnológicas se utilizan de forma superficial, ya que los estudiantes-usuarios solo se encargan de replicar discursos establecidos en torno a la imagen. Gutiérrez (2016) describe el problema entre la creación artística y su fundamentación en el entorno contemporáneo:

(...) se ha identificado que la digitalización cultural y tecnológica ha avanzado a una velocidad muy superior a la de la alfabetización digital. De manera que la ubicuidad de los sistemas digitales en las sociedades contemporáneas, no se compagina con el conocimiento general de las estructuras conceptuales que subyacen y articulan a dichos sistemas y a todo el conocimiento que por ellos circula. (p.40)

Este desfase curricular genera una crisis en los propósitos del aprendizaje, pues la posibilidad de innovación se ve supeditada a la oferta de repertorios visuales procesados. El analfabetismo tecnológico que se vive en diferentes espacios académicos ha desconectado a los creadores de la comprensión de fenómenos físicos que son suplidos por las diferentes algoritmos e interfaces, alejando al estudiante de la experiencia por la práctica. Y la práctica constituye la identidad del individuo:

"Desarrollar una práctica exige la formación de una comunidad cuyos miembros pueden reconocerse mutuamente y, con ello, reconocerse mutuamente como participantes. En consecuencia, la práctica supone la negociación de maneras de llegar a ser una persona en ese contexto" (Wenger, 2001, p. 187) 
En contraste, un caso educativo como el del Reino Unido experimentó un cambio en la oferta de la enseñanza fotográfica en la década de los 60 , pasando de lo vocacional al fortalecimiento y escolarización del área. Este proceso tuvo un giro radical a comienzos de la década de 1970 con la incursión de Victor Burgin en el programa de Fotografía del Polytechnic of Central London (PCL), quien sustentó la estructura curricular en tres pilares: Historia, Semiología y Sociología, centrando esta nueva ola de la enseñanza de la fotografía en su naturaleza social, como propuesta artística y de comunicación y ya no únicamente como una herramienta de masas o medio eficiente de la producción de la imagen (McWilliams, 2009, p. 244). Como consecuencia, al final de la década de 1970, surge la denominada New Photography Theory (Smith \& Lefley, 2016), que definió nuevos parámetros para entender el fenómeno de masificación de la imagen fotográfica y sus diferentes significados, siendo revaluado el valor del registro como documento. Bajo este movimiento, que tuvo injerencia específica en Europa, artistas y teóricos reclamaron el valor de la fotografía más allá de la idea del registro, abriendo la discusión sobre el valor ideológico de la práctica fotográfica, que influyó en muchas de las prácticas académicas de la educación superior (p. 346). Este viraje curricular modificó los contenidos y fue un reto al laissez-faire de la tradición académica, cambiando las dinámicas curriculares y haciendo que la enseñanza fotográfica pasara de ser algunas asignaturas de contenidos dispersos aglutinados bajo el concepto de Fine Arts a adquirir un lenguaje propio en los estudios culturales y de las ciencias humanas (Watney, 1984, p. 67).

El caso británico demuestra que la inclusión del contexto de la práctica en el currículo, potencia la relación de tensión dinámica entre ambos dispositivos (el currículo y el fotográfico) permitiendo reconocer en los individuos roles e identidades propios y no definidos por la estructura académica. El sentido de lo profesional en este caso no consiste en los avales institucionales que desestiman la trayectoria y la experiencia de los practicantes en los propios contextos, sino que más bien se construye desde la conciencia de lo situacional. Un currículo que está relacionado con un contexto cognitivo y con unos fenómenos sociales dados en un tiempo y espacio específicos: “(...) el aprendizaje es una dimensión integral e inseparable de la práctica social” (Lave \& Wenger, 1991, p. 31).

\section{De la manada al colectivo}

A diferencia del caso británico, en Colombia la inclusión de la Fotografía como área específica de estudio ha sido por cuestiones procedimentales y de eficiencia, pero no contemplando las posibilidades de las reflexiones de los discursos visuales. Como reacción a esta condición han surgido múltiples colectivos alternativos a los espacios oficializados que han empezado a aportar nuevas posibilidades de aprendizaje en otros contextos. Si bien, es imposible separar la práctica fotográfica de una serie de procedimientos tecnológicos, la idea de práctica e identidad (Lave \& Packer, 2011; Lave \& Wenger, 1991; Wenger, 2001), el aprendizaje situado en el contexto provee nuevas posibilidades en los que la argumentación visual se construye desde una propuesta de colectivo, muchas veces estructurada desde el entorno académico pero que se desmarca de la tradición curricular impuesta por la estructura universitaria. 
Esta estructura emergente no es de orden piramidal ni se fundamenta en modelos didácticos, ni se programa en un calendario académico. Por el contrario, desde lo vivencial y cotidiano de sus participantes, construye una identidad en el mundo que permite elaborar nuevos significados. Los supuestos tiempos muertos del grupo son espacio de propuestas enmarcadas en lo que la actualidad requiere, contrario al programa académico establecido que,en un número de semanas y de actividades, pretende ser suficiente temáticamente. El currículo del colectivo contempla además otro aspecto que es vital para el proceso de aprendizaje: la trayectoria del individuo, asimilado también como una oportunidad de aprendizaje para los otros miembros, por ende, el proceso de aprendizaje es horizontal y de diálogo constante entre los participantes.

En varios casos, dichos colectivos surgen como una reacción frente a la enseñanza establecida en la universidad, y en esa reacción surge una posición política que obliga a sus integrantes a ser más conscientes del contexto y construyen un propósito que los define en el mundo desde su quehacer. Esta voz en el mundo nos aleja de la hedonia depresiva y dependiente de una tendencia tecnológica, permitiendo nuevas búsquedas en las formas de hacer de acuerdo a las expectativas personales. De esta manera los dispositivos logran una paridad y se aúnan en un currículo proyectual, en el que el hecho tecnológico hace sentido en la práctica y no significa en sus posibilidades tecnológicas al sujeto.

Estas comunidades de práctica (Wenger, 2001) son exogámicas y sus participantes tienen múltiples filiaciones con aprendizajes experienciales que son incorporados en la comunidad, y no dejados a un lado para adquirir una nueva personalidad, a diferencia del entro a la universidad para volverme se convierte en un hacer desde el ser y así poder ser en el mundo, construyendo un nuevo significado tanto personal como social.

Por lo tanto, pareciera que el reto central de los estudios curriculares particularmente en torno a la fotografía radica principalmente en cerrar la brecha entre lo que pasa en la institución universitaria y los fenómenos que suceden en el contexto. Las instituciones son fuente de estabilidad y de respaldo, condiciones de las que carecen los colectivos que muchas veces hacen que su duración en el tiempo sea efímera o una tarea a título personal de uno de sus miembros. En este orden de ideas, cerrar la brecha implica no únicamente hacer grandes inversiones económicas en tecnologías sino realmente hacerlas asequibles y comprensibles en su naturaleza, que su apropiación surja de la cotidianidad y, por qué no, sean el resultado de prácticas de improvisación en dentro de la participación para construir nuevos significados en fotografía.

\section{Listas de Referencias Bibliográficas}

Agamben, G. (2011). ¿Qué es un dispositivo? Sociológica, 26 (73)(Mayo-Agosto), 249-264. Bertrand, Y., \& Houssaye, J. (1999). Pédagogie and didactique: An incestuous relationship. Instructional Science, 27(1/2), 33-51. https://doi.org/10.1023/A:1003026309033

Brea, J. L. (2010). Las tres eras de la imagen: imagen-materia, film, e-image. (Akal, Ed.). Madrid. 
Fisher, M. (2017). Realismo Capitalista: ¿no hay alternativa? Buenos Aires: Caja Negra Editores.

Goodson, I. (2000). El cambio en el currículum. Barcelona: Octaedro.

Gutiérrez Jiménez, E. (2016). Material digital y creación artística. Universidad Nacional de Colombia. Sede Bogotá. Retrieved from http://www.bdigital.unal.edu.co/54303/

Hamilton, D. (1999). The pedagogic paradox (or why no didactics in England?). Pedagogy, Culture and Society, 7(1), 135-152. https://doi.org/10.1080/14681369900200048

Hobsbawm, E. J., \& Ranger, T. (2012). La invención de la tradición. Barcelona: Crítica.

Lave, J., \& Packer, M. (2011). Hacia una ontología social del aprendizaje. Revista de Estudios Sociales No.35, (40), 12-22. https://doi.org/10.7440/res40.2011.02

Lave, J., \& Wenger, E. (1991). Situated learning: legitimate peripheral participation. (M. Espíndola \& C. Alfaro, Trans.). Cambridge [England] ; New York: Cambridge University Press.

Lave, J., Wenger, E., Espíndola, M., \& Alfaro, C. (1991). Situated learning: legitimate peripheral participation. Learning in doing. Cambridge [England] ; New York: Cambridge University Press.

McWilliams, M. (2009). The Historical Antecedents of Contemporary Photography Education: A British Case Study, 1966-79. Photographies, 2(2), 237-254. https://doi. org/10.1080/17540760903116697

Smith, P., \& Lefley, C. (2016). Rethinking photography: histories, theories, and education. New York: Routledge.

Watney, S. (1984). Photography - Education - Theory. Screen, 25(1), 67 '73.

Wenger, E. (2001). Comunidades de práctica: aprendizaje, significado e identidad. Paidós.

\begin{abstract}
The undeniably close relationship between photography and technology has created a convoluted curriculum that tends to be outdated. This condition means that photography programs continue to inherit structures from other curricular traditions, denying them the possibility to construct their own content in the field, which causes an endogamous visual phenomenon in which trends are constantly repeated, something which is typical of these times in which political and economic systems societies made up not of citizens but rather consumers. The alternative is to investigate the context and change this invisible curriculum to one that is active and which permeates the institutional structure and connects it to the everyday.
\end{abstract}

Keywords: Photography education - Photography in Colombia - Dispositif - Apparatus Learning - Curriculum

Resumo: As inegáveis conexões entre a fotografia e a tecnologia têm sido um currículo com problemas que muitas vezes está desatualizado em seu contexto. Esta condição faz fotografia herdeiros de programas de outras tradições curriculares, anulando a possibilidade da construção de seu próprio conteúdo no campo, com implicações para um fenômeno visual de consanguinidade repetem-se quais as tendências de maneira constante, típico destes tempos em que os sistemas políticos e económicos são decantados por não de pessoas mas das so- 
ciedades de consumo. A alternativa é investigar o contexto e fazer desse ativo um currículo invisível que eu permeie a estrutura institucional e vida mais perto de todos os dias.

Palavras chave: Fotografia - tecnologia - sociedades de consumo

[Las traducciones de los abstracts fueron supervisadas por el autor de cada artículo] 